\title{
Field evaluation of the Copal UA-231 automatic sphygmomanometer
}

\author{
STEPHEN ROGERS, ${ }^{1}$ GEORGE DAVEY SMITH, ${ }^{2 *}$ AND WENDY DOYLE ${ }^{2}$ \\ From the MRC Epidemiology Unit, ${ }^{4} 4$ Richmond Road, Cardiff CF2 3AS; and the Institute of Health Promotion, ${ }^{2}$ \\ Heartbeat Wales, 24 Park Place, Cardiff CF1 3BA
}

SUMMARY Automated sphygmomanometers should be evaluated in field studies before being recommended for epidemiological use. In this study an automated sphygmomanometer, the Copal UA-231, was evaluated on the basis of duplicate blood pressure measurements, one with this machine and one with a Hawksley random zero machine, taken on 1536 participants in a health survey. The Copal-random zero differences had a mean of $2.3 \mathrm{~mm} \mathrm{Hg}$ for systolic blood pressure and $1.9 \mathrm{~mm} \mathrm{Hg}$ for diastolic pressure, the Copal reading higher than the random zero. The standard deviations of these differences were similar to the standard deviations of the differences between two random zero measurements taken on subjects in a separate survey. However, Copal-random zero differences varied systematically with blood pressure levels. In this study a $10 \mathrm{~mm} \mathrm{Hg}$ increase in systolic blood pressure was associated with a $1.22 \mathrm{~mm} \mathrm{Hg}$ increase in the Copal-random zero difference and a $10 \mathrm{~mm} \mathrm{Hg}$ increase in diastolic blood pressure was associated with a $1.15 \mathrm{~mm} \mathrm{Hg}$ increase in the Copal-random zero difference.

The Copal UA-231 is recommended for use in field surveys, but it should be recognised that a small systematic increase in Copal-random zero difference with increasing blood pressure may complicate interpretation of epidemiological associations.

The importance of validating automated blood pressure measuring instruments, preferably by investigators independent of the manufacturers, has been recently stressed. ${ }^{1}$ In this paper we present further data on the Copal UA-231, a light, compact automatic sphygmomanometer which compared favourably with the Hawksley random zero sphygmomanometer in a small method agreement study published in this Journal. ${ }^{2}$ Korotkoff sound detection is by a microphone which is incorporated into the cuff. Systolic measurement is determined at Korotkoff phase 1 (the initial detection of returning blood flow) and the diastolic measurement at Korotkoff phase 5 (the completed restoration of blood flow). Because the effects of Korotkoff sound interpretation by the investigator are eliminated it has been suggested that the use of the instrument may reduce possible sources of observer error and observer bias in the measurement of blood pressure, and the instrument has since been used in a number of

\footnotetext{
* Present address: University College Hospital and Middlesex Hospital Medical School, Department of Community Medicine, 66-72 Gower Street, London WCIE 6EA.
}

epidemiological studies. ${ }^{3-5}$ In this report we present data from the Heartbeat Wales clinical survey, which allowed a detailed evaluation of the performance of the automatic sphygmomanometer under field conditions.

\section{Methods}

The clinical survey population was selected from a sub-sample of subjects responding to the community component of the Welsh Heart Health Survey 1985. Those accepting attended one of 46 clinics in the Principality for interview and examination. The participants consisted of 1832 males and females between the ages of 12 and 65 .

Two blood pressure measurements were taken on each participant, one using the Copal UA-231 and one using a Hawksley random zero sphygmomanometer. The first reading was taken alternately with the Copal UA-231 and the Hawksley random zero sphygmomanometer, each according to a strict protocol. ${ }^{4}$ The Hawksley machine was one operating with a $0-20 \mathrm{~mm} \mathrm{Hg}$ range of random zero readings. 
The operation of the Copal UA-231 has been described previously. ${ }^{2}$ In the Heartbeat Wales clinical survey the signal generator was disconnected, and the noise made by bladder inflation was demonstrated to the participant before blood pressure measurement. A peak inflation pressure of $180 \mathrm{~mm} \mathrm{Hg}$ was used and this was increased to $220 \mathrm{~mm} \mathrm{Hg}$ if the first pressure proved inadequate. The standard cuff was used for all measurements.

A peak inflation of $220 \mathrm{~mm} \mathrm{Hg}$ was used with the random zero sphygmomanometer and increased if the pulse could still be palpated. A deflation rate of approximately $2 \mathrm{~mm} \mathrm{Hg}$ per second was used. The systolic pressure was recorded at the appearance of the first sound and the diastolic pressure at the disappearance of the Korotkoff sounds. Observers were trained using the Rose training tapes ${ }^{6}$ before the survey began. One of three cuff sizes was used (small adult, standard adult or large adult), depending on the arm circumference.

All blood pressure measurements were made on the right arm (unless missing, injured or otherwise unsuitable), with the subject seated and the arm supported at heart level. Each blood pressure measurement was preceded by a three minute resting period and pulse measurement. Arm circumference was measured to the next succeeding millimetre during anthropometry. Height without shoes was recorded for all participants using an OPCS stadiometer, and weight in light clothing was measured on a Soehnle electronic scale.

\section{Results}

A single observer (WD) made blood pressure observations on 1755 individuals, 1536 of them using the same Copal UA-231 and random zero sphygmomanometer. In 789 individuals the Copal reading was taken first and in 747 individuals the Hawksley reading was taken first. Thus the alternate allocation may not have been entirely satisfactorythe observer appears to have had a preference to take the Copal measurement first. However, as can be seen

Table 1 Characteristics of sample by order of blood pressure measurement ${ }^{l}$

\begin{tabular}{lcc}
\hline & $\begin{array}{l}\text { COPAL Ist } \\
n=789\end{array}$ & $\begin{array}{l}\text { COPAL 2nd } \\
n=747\end{array}$ \\
\hline Age, years (mean, SD) & $39.1(14.6)$ & $39.8(14 \cdot 1)$ \\
Sex: \% males & 51 & 52 \\
$\%$ females & 49 & 48 \\
Body mass index, kg/m ${ }^{2}$ (mean, SD) & $24.4(3.8)$ & $24.7(4.2)$ \\
Systolic blood pressure, mm Hg (mean, SD) & $125.8(17.8)$ & $124.5(17.5)$ \\
Diastolic blood pressure, mm Hg (mean, SD) & $78.0(11.2)$ & $77.1(11 \cdot 1)$ \\
Pulse, beat per minute (mean, SD) & $69.4(10.0)$ & $70.4(9.8)$ \\
Arm circumference, cm (mean, SD) & $29.6(3.4)$ & $29.8(3.6)$ \\
\hline
\end{tabular}

\footnotetext{
1 Based on less than $\mathbf{n}$ participants for some variables due to missing values.
}

from table 1 , there were no significant differences between the two groups in a number of variables examined.

Table 2 shows systolic and diastolic blood pressure by order and by instrument. There was an order effect for systolic pressure of $+2.3 \mathrm{~mm} \mathrm{Hg}(95 \%$ confidence limits: $+1.6,+3.0 \mathrm{~mm} \mathrm{Hg}$ ), but the order effect for diastolic pressure was not statistically significant. Since the design was approximately balanced and the order effects were small, they have been ignored for the purpose of these analyses. There was no evidence of an interaction between order and instrument. The mean difference between the Copal and Hawksley for all participants was $+2.3 \mathrm{~mm} \mathrm{Hg}(95 \% \mathrm{CL}:+2 \cdot 0,+2 \cdot 7$ $\mathrm{mm} \mathrm{Hg}$ ) for systolic blood pressure, and $+1.9 \mathrm{~mm} \mathrm{Hg}$ $(95 \% \mathrm{CL}:+1.6,+2.2 \mathrm{~mm} \mathrm{Hg})$ for diastolic blood pressure.

Table 2 Systolic and diastolic blood pressure by order and machine type ${ }^{l}$

\begin{tabular}{|c|c|c|}
\hline & $\begin{array}{l}\text { Ist reading } \\
\text { COPAL } \\
(n=783)\end{array}$ & $\begin{array}{l}\text { 2nd reading } \\
\text { Random } \\
\text { Zero }\end{array}$ \\
\hline \multirow{2}{*}{$\begin{array}{l}\text { Systolic blood pressure (mean, SD) } \\
\text { Diastolic blood pressure (mean, SD) }\end{array}$} & $127 \cdot 5(19 \cdot 1)$ & $124.0(16.9)$ \\
\hline & $\begin{array}{l}\text { lst reading } \\
\text { Random } \\
\text { Zero } \\
(n=736)\end{array}$ & $\begin{array}{l}\text { 2nd reading } \\
\text { Copal }\end{array}$ \\
\hline $\begin{array}{l}\text { Systolic blood pressure (mean, SD) } \\
\text { Diastolic blood pressure (mean, SD) }\end{array}$ & $\begin{array}{r}124.0(17 \cdot 1) \\
76 \cdot 0(10 \cdot 5)\end{array}$ & $\begin{array}{r}125 \cdot 1(18 \cdot 7) \\
78 \cdot 1(11 \cdot 7)\end{array}$ \\
\hline
\end{tabular}

${ }^{1}$ Results from 17 individuals have been excluded because of missing values.

The degree of agreement between readings of blood pressure on different instruments is indexed by the standard deviation of the differences between the readings. ${ }^{7}$ Since in this study the order of the readings is roughly balanced, this measure reflects both the true difference between two blood pressure readings taken three minutes apart and a component due to measurement. The standard deviations of the differences were $7 \cdot 11$ for systolic blood pressure and 5.96 for diastolic blood pressure. We compared this to the standard deviation of the difference between two readings both taken using a random zero machine. These data were collected on 237 subjects who had two random zero blood pressure recordings taken by one observer (SR) during the Cardiff arm of Intersalt. ${ }^{8}$ To balance the order effect in 119 of the readings the difference was computed as the first reading minus the second reading, whilst for 118 of the readings the difference was computed as the second reading minus the first reading. The standard deviations of these differences were 6.64 for systolic blood pressure and 6.22 for diastolic blood pressure, closely similar to the standard deviations of the Copal-random zero differences. 
The distribution of random zero-Copal differences by age, sex (females $=0$, males $=1)$, body mass index (BMI), blood pressure (mean of two readings), pulse (mean of two readings) and arm circumference was then examined in a series of univariate analyses. Systolic differences were significantly associated with sex $(p<0.001), B M I(p<0.001)$, mean systolic pressure $(\mathrm{p}<0.001)$, pulse $(\mathrm{p}<0.001)$ and arm circumference $(p<0.001)$ in univariate analyses. Diastolic differences were associated with age $(p<0.001)$, BMI $(p<0.001)$, mean diastolic pressure $(p<0.001)$ and arm circumference $(p<0.001)($ table 3$)$. Whenage, sex, BMI, blood pressure, pulse and arm circumference were entered into a stepwise multiple regression analysis with systolic difference as the dependent variable, systolic pressure entered the regression model first followed by age, pulse and sex. Neither BMI nor arm circumference added significantly to this basic model. With diastolic difference as the dependent variable diastolic pressure entered first followed by arm circumference, then sex. Neither BMI nor age added significantly to the model. The regression coefficients for the stepwise models are presented in table 4 .

Table 3 Regression coefficients (SEs) of variables associated with systolic and diastolic differences. (Systolic differences were regressed on mean systolic pressure and diastolic differences were regressed on mean diastolic pressure .)

\begin{tabular}{lll}
\hline & Systolic differences & Diastolic differences \\
\hline Age & $+0.016(0.013)$ & $+0.067(0.011)^{*}$ \\
Sex & $+2.36(0.36)^{*}$ & $-0.08(0.30)$ \\
Body mass index & $+0.154(0.048)^{*}$ & $+0.306(0.039)^{*}$ \\
Mean blood pressure & $+0.112(0.010)^{*}$ & $+0.134(0.014)^{*}$ \\
Mean pulse & $-0.063(0.018)^{*}$ & $-0.025(0.015)$ \\
Arm circumference & $+0.247(0.054)^{*}$ & $+0.347(0.044)^{*}$ \\
\hline${ }^{*} \mathrm{p}<0.001$ & &
\end{tabular}

Table 4 Partial regression coefficients (SEs) of variables associated with systolic and diastolic differences in stepwise multiple regression models, with constants.

\begin{tabular}{ll}
\hline Variable & Systolic differences \\
\hline Mean systolic pressure & $+0.122(0.012) \dagger$ \\
Age & $-0.057(0.014) \dagger$ \\
Mean pulse & $-0.057(0.018)^{*}$ \\
Sex & $+0.99(0.37)^{*}$ \\
Constant & -7.225 \\
\hline Variable & Diastolic Differences \\
\hline Mean diastolic pressure & $+0.115(0.015) \dagger$ \\
Arm circumference & $+0.235(0.049) \dagger$ \\
Sex & $-1.04(0.31)^{*}$ \\
Constant & -13.426 \\
\hline
\end{tabular}

* $p<0.01, \quad+p<0.001$

\section{Discussion}

This field evaluation of the Copal complements previous studies, ${ }^{29}$ by providing information on its utility as a survey instrument. Comparison with the current standard survey machine, the Hawksley random zero sphygmomanometer, reveals small systematic differences of $2.3 \mathrm{~mm} \mathrm{Hg}$ in systolic blood pressure and $1.9 \mathrm{~mm} \mathrm{Hg}$ in diastolic blood pressure, the Copal reading being higher than the random zero reading. These differences are certainly no greater than those expected between two observers, and might not be the same if a different observer had used the two machines. However it is noteworthy that three studies have revealed that when the same observers use the random zero and a standard mercury sphygmomanometer, the random zero reads lower by similar amounts to those shown here. ${ }^{10-12}$

This evaluation is based on data recorded during a survey, and readings were not taken blindly. There is a possibility that the observer may unconsciously attempt to obtain a second reading similar to the first. This could not apply when the automatic machine takes the second reading. The use of a random zero machine makes if difficult, but not impossible, to bias second readings. The finding that agreement between the machines was no worse when the automatic instrument was used second suggests that no such biasing of readings occurred.

The sets of systolic and diastolic blood pressure readings taken by the Copal instrument demonstrate a greater variance than the corresponding sets taken with the random zero instrument (table 2). This is at least partly due to the dependence of the Copalrandom zero difference upon mean blood pressure level. The regression model outlined in table 4 suggests that Copal gives lower readings than the random zero in the lowest part of the blood pressure distribution, with the Copal readings becoming increasingly high as mean blood pressure increases. A $10 \mathrm{~mm} \mathrm{Hg}$ increase in mean systolic blood pressure goes with a $1.22 \mathrm{~mm}$ $\mathrm{Hg}$ increase in the systolic Copal-random zero difference. A $10 \mathrm{~mm} \mathrm{Hg}$ increase in mean diastolic pressure goes with a $1.15 \mathrm{~mm} \mathrm{Hg}$ increase in the diastolic difference. This observation may be important for the interpretation of epidemiological associations where the Copal is used to make blood pressure measurements. Copal-random zero differences also show statistically significant associations with age, pulse, sex and arm circumference, but these are too small to be of importance.

The Copal UA-231 is a useful instrument for epidemiological survey work. It is light, compact and simple to use. It removes some of the observer variation in the measurement of blood pressure, ie that 
due to variation in recognition of Korotkoff sounds, rate of deflation and reading of the mercury column; it eliminates some sources of observer bias; and it is a useful way of quantifying observer drift if both automated and manual readings are taken. It compared well with the Hawksley random zero sphygmomanometer in this study, but it should be recognised that the small systematic increase in Copalrandom zero differences with increasing blood pressure level may be sufficient to complicate the interpretation of some epidemiological associations. It is recommended for use in epidemiological field surveys with this reservation.

The authors would like to thank Karin Phillips for preparing the data tape.

Correspondence and reprint requests to Dr George Davey Smith, University College Hospital and Middlesex Hospital Medical School, Department of Community Medicine, 66-72 Gower St, London WC1E 6EA.

\section{References}

${ }^{1}$ O'Brien E, Petrie JC, Littler WA, De Swiet M. Standards for blood pressure measuring devices. $\mathrm{Br} \mathrm{Med} \mathrm{J} \mathrm{1987;} \mathrm{294:}$ 1245-6.

${ }^{2}$ Gallacher JEJ, Yarnell JWG, Rogers S, Sweetnam P. Automatic measurement of blood pressure: evaluation of the Copal UA-231 automatic sphygmomanometer. $J$ Epidemiol Community Health 1985; 39: 220-3.
${ }^{3}$ The Caerphilly Collaborative Group. Project description and manual of operations. Cardiff: MRC Epidemiology Unit, 1985.

${ }^{4}$ Directorate of the Welsh Heart Programme. Welsh Heart Health Survey 1985. Clinical Manual. Cardiff: Heartbeat Report No. 3, 1986.

${ }^{5}$ Padfield PL, Lindsay BA, McLaren JA, Pirie A, Rademaker $\mathbf{M}$. Changing relation between home and clinic blood-pressure measurements: do home measurements predict clinic hypertension? Lancet 1987, ii: $322-4$.

${ }^{6}$ Rose G. Standardisation of observers in blood pressure measurement. Lancet 1965; i: 673-4.

${ }^{7}$ Bland JM, Altman DG. Statistical methods for assessing agreement between two methods of clinical measurement. Lancet 1986; i: 307-10.

${ }^{8}$ Intersalt Co-operative Research Group. Intersalt Study: An international co-operative study on the relation of blood pressure to electrolyte excretion in populations. 1 . Design and methods. J Hypertension 1986; 4: 781-7.

${ }^{9}$ Lindsay BA, Rademaker M, Padfield PL. Evaluation of a portable electronic sphygmomanometer (UA 251/UA 231). Clin Sci 1985; 68: 67p-68p.

${ }^{10}$ Evans JG, Prior IAM. Experience with the random-zero sphygmomanometer. Br J Prev Soc Med 1970; 24: 10-5.

${ }^{11}$ Labarthe DR, Hawkins CM, Remington RD. Evaluation of performance of selected devices for measuring blood pressure. Am J Cardiol 1973; 32: 546-53.

12 De Gaudemaris R, Folsom AR, Prineas J, Luepker RV. The random-zero versus the standard mercury sphygmomanometer: a systematic blood pressure difference. Am J Epidemiol 1985; 121: 282-90.

Accepted for publication May 1988 